\title{
Banning front-of-package food labels: First Amendment constraints on public health policy
}

\author{
Timothy D Lytton*
}

Albert \& Angela Farone Distinguished Professor of Law, Albany Law School, Albany, NY, USA

Submitted 29 April 2010: Accepted 18 August 2010: First published online 17 November 2010

\begin{abstract}
In recent months, the FDA has begun a crackdown on misleading nutrition and health claims on the front of food packages by issuing warning letters to manufacturers and promising to develop stricter regulatory standards. Leading nutrition policy experts Marion Nestle and David Ludwig have called for an even tougher approach: a ban on all nutrition and health claims on the front of food packages. Nestle and Ludwig argue that most of these claims are scientifically unsound and misleading to consumers and that eliminating them would 'aid educational efforts to encourage the public to eat whole or minimally processed foods and to read the ingredients list on processed foods'. Nestle and Ludwig are right to raise concerns about consumer protection and public health when it comes to front-of-package food labels, but an outright ban on front-of-package nutrition and health claims would violate the First Amendment. As nutrition policy experts develop efforts to regulate front-of-package nutrition and health claims, they should be mindful of First Amendment constraints on government regulation of commercial speech.
\end{abstract}

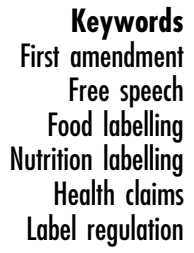

In recent months, the Food and Drug Administration (FDA) has begun a crackdown on misleading nutrition and health claims on the front of food packages by issuing warning letters to manufacturers and promising to develop stricter regulatory standards. Leading nutrition policy experts, Marion Nestle and David Ludwig, have called for an even tougher approach: a ban on all nutrition and health claims on the front of food packages ${ }^{(1)}$. Nestle and Ludwig argue that most of these claims are scientifically unsound and misleading to consumers and that eliminating them would aid educational efforts to encourage the public to eat whole or minimally processed foods and to read the ingredients list on processed foods $^{,(1)}$. Nestle and Ludwig are right to raise concerns about consumer protection and public health when it comes to front-of-package food labels, but an outright ban on front-of-package nutrition and health claims would violate the First Amendment. As nutrition policy experts in academia and the FDA develop strategies to regulate front-of-package nutrition and health claims, they should be mindful of First Amendment constraints on government regulation of commercial speech.

\section{Different types of nutrition and health claims on food labels}

In order to understand how the First Amendment applies to the regulation of front-of-package nutrition and health claims, it is helpful to distinguish among different types of claims (see Fig. 1).

FDA regulations distinguish among four general types of nutrition and health claims on food labels: health claims, structure/function claims, dietary guidance, and nutrient content claims. Health claims are claims that characterize the relationship between a food or food component and a disease or a health-related condition $^{(2-4)}$. An example of a health claim would be 'diets low in sodium may reduce the risk of high blood pressure, a disease associated with many factors, ${ }^{\text {(4) }}$. Only health claims approved by the FDA may be placed on food packages ${ }^{(5,6)}$. Structure/function claims describe the general effect of nutrients on the normal structure or function of the human body, e.g. 'calcium builds strong bones $^{\text {,(4) }}$. Structure/function claims do not require FDA approval so long as they are truthful and not misleading $^{(4)}$. Dietary guidance statements refer more generally to dietary advice - 'dietary patterns, practices and recommendations that promote health' - and they typically refer broadly to a category of foods rather than specific nutrients or substances, e.g. 'eat five servings daily of fruits and vegetables, ${ }^{(4,6)}$. These claims do not require FDA approval and may be used so long as they are truthful and not misleading ${ }^{(4)}$. Nutrient content claims are claims that describe the level of a nutrient in a food $^{(2,7)}$. Since nutrient content claims have been the primary target of the recent FDA crackdown on front-ofpackage nutrition claims and the focus of current agency 


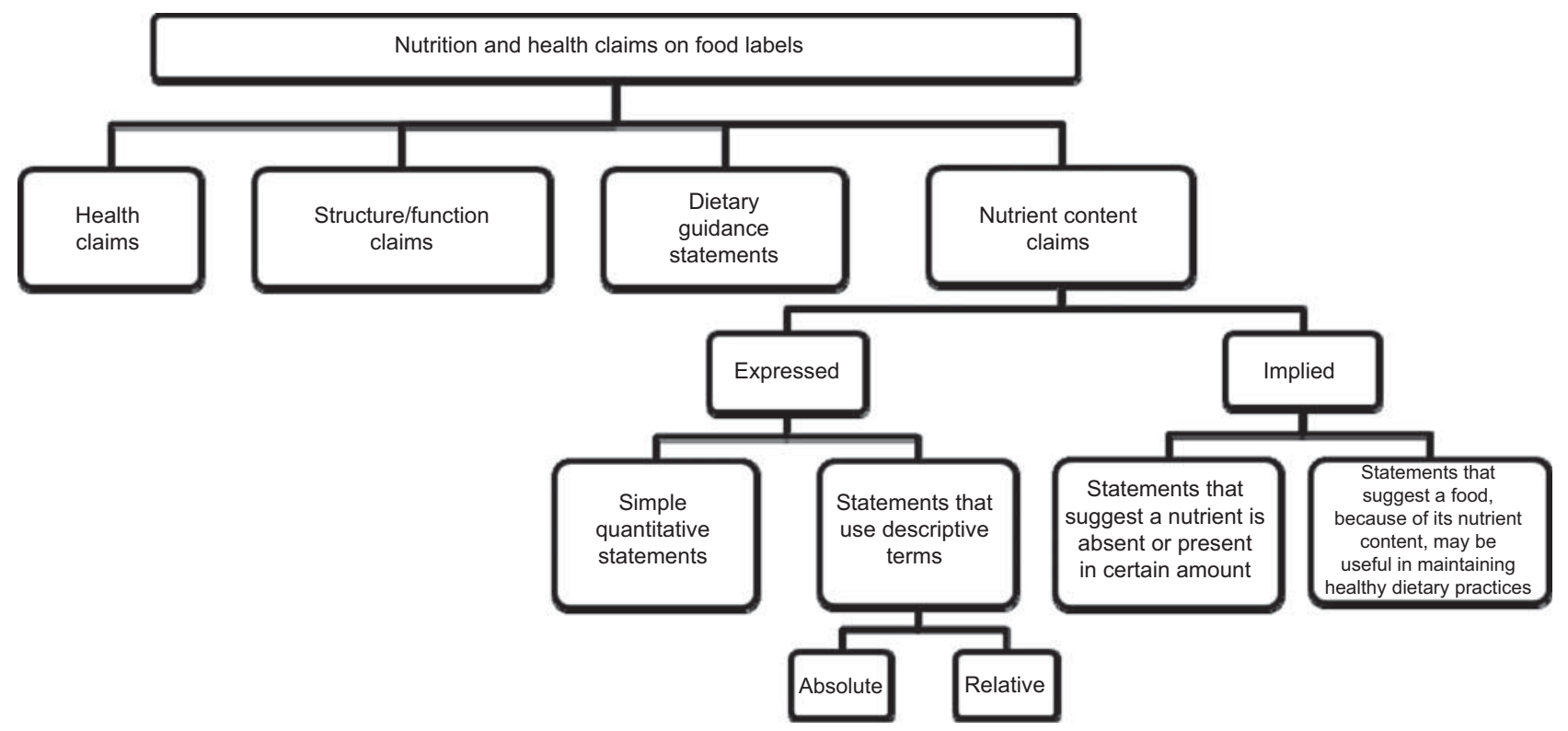

Fig. 1 Taxonomy of nutrition and health claims

efforts to develop new label regulations, it is useful to distinguish the different types of nutrient content claims.

Nutrient content claims may be expressed or implied ${ }^{(7)}$. Expressed nutrient content claims describe the level of a nutrient in a food by referring directly to the level of nutrients, e.g. sodium or calcium ${ }^{(7,8)}$. Expressed nutrient content claims that take the form of simple quantitative statements, such as ' $200 \mathrm{mg}$ of sodium', may be used for any level of a nutrient so long as they are accurate ${ }^{(4,7)}$. Expressed nutrient content claims that employ descriptive terms, such as 'low in sodium' or 'high in fiber', may be made only for nutrients for which FDA has established a Reference Daily Intake (RDI) or Daily Reference Value (DRV), may be used only if the food meets the specified threshold requirements for the nutrient, and may use only descriptive terms approved by the FDA ${ }^{(8-18)}$. Importantly, expressed nutrient content claims that use descriptive terms not specifically approved by the FDA are prohibited $^{(9)}$, although manufacturers may petition the FDA for approval of such terms ${ }^{(8,19)}$.

Descriptive terms may be absolute or relative. Examples of absolute terms are 'high', 'low' and 'free', whereas examples of relative terms include 'more', 'reduced' and 'light ${ }^{(8-18)}$. Absolute nutrient content claims must conform to standards based on a percentage of the RDI or DRV present in reference amounts customarily consumed (RACC) as defined by FDA and US Department of Agriculture regulations $^{(8,20)}$. For example, a tub of yoghurt labelled 'high in calcium' must contain at least $20 \%$ of the RDI of calcium per $225 \mathrm{~g}$ of yoghurt (the RACC for yoghurt $)^{(8,9)}$. Relative nutrient content claims must name the reference food to which the product is being compared, and they must state the percentage or fraction of the amount of the nutrient in the reference food by which the nutrient has been modified ${ }^{(7,8)}$. For example, a label for reduced-sodium potato chips must include a statement such as 'contains 30 per cent less sodium than regular potato chips'. Nutrient content claims on foods that contain levels of fat, saturated fat, cholesterol and sodium above specified threshold amounts must be accompanied by a referral statement to the Nutrition Facts panel, such as: 'See nutrition information for fat content ${ }^{(7,21)}$.

Implied nutrient content claims are of two types. The first is statements that describe a food or food ingredient in a manner suggesting that a nutrient is absent or present in a certain amount ${ }^{(7)}$. For example, the statement 'high in oat bran' implies that the food is high in fibre. Such label statements must either conform to the standards for express nutrient content claims or include a disclaimer, such as 'not a good source of fiber' ${ }^{\text {, } 7,8)}$.

The second type of implied nutrient content claim is statements that a food, because of its nutrient content, may be useful in maintaining healthy dietary practices, e.g. 'healthy, contains $3 \mathrm{~g}$ of $\mathrm{fat}^{(7)}$. FDA considers the use of the term 'healthy', when 'placed in a nutritional context', to constitute an implied nutrient content claim and has defined the term accordingly ${ }^{(22)}$. Foods that are labelled 'healthy', or any derivative of the term such as 'healthier' or 'healthful', must not exceed specific thresholds of fat, saturated fat, sodium and cholesterol and must contain requisite amounts of other nutrients such as vitamins A, C, calcium, iron, protein and fibre, depending on the food ${ }^{(22,23)}$.

Simple nutrient content claims like 'fat-free' and 'fortified with nine essential vitamins and iron' have long appeared on the front of food packages. But a new generation of front-of-package labels presents more and more complex nutrition information, raising concerns among academic and government policy experts that 
consumers may be confused or misled. Examples include the General Mills' Nutrition Highlights Panel that shows the quantities of six nutrients at a glance, the American Heart Association's Heart Check Mark that designates foods as healthy, and the now infamous Smart Choices Logo that appeared on sweetened children's breakfast cereals such as Froot Loops and Cocoa Krispies as well as on full-fat mayonnaise and ice cream before it was discontinued in the wake of an FDA warning letter and an investigation by the Connecticut Attorney General ${ }^{(24-26)}$. This new generation of nutrient content claims also includes shelf labels like the NuVal Nutritional Scoring System, which rates the overall nutritional value of food items from 1 to 100 .

\section{First Amendment limits on Food and Drug Administration regulation of nutrition and health claims}

Litigation over the standard for FDA approval of health claims has resulted in court opinions that set First Amendment constraints on the regulation of all food label claims. The Nutrition Labeling and Education Act of 1990 authorized health claims for conventional foods where the Secretary of Health and Human Services 'determines, based on the totality of publicly available scientific evidence ... that there is significant scientific agreement ... that the claim is supported by such evidence'. With regard to dietary supplements, the Act provided for approval of health claims 'subject to a procedure and standard ... established by regulation of the Secretary'. In 1993, the FDA published regulations to implement these statutory provisions in which the agency adopted the significant scientific agreement (SSA) standard for the approval of health claims on both conventional foods and dietary supplements. In 1995, dietary supplement manufacturers challenged the agency's SSA standard and the agency's refusal to approve four particular health claims as a violation of the First Amendment's protection of commercial speech ${ }^{(27)}$.

The US Supreme Court has held that a government restriction on commercial speech is unconstitutional unless the government can establish that the restriction directly advances a substantial government interest and that there is a 'reasonable fit' between the restriction and the interest it is designed to serve ${ }^{(28)}$. In deciding challenges to the SSA standard for health claims on dietary supplements, lower federal courts have interpreted 'reasonable fit' to mean that an outright ban on such claims would be an excessively broad means of advancing the government's interest in preventing consumer fraud if the health claims at issue could be presented in a nonmisleading way using disclaimers or other qualifications ${ }^{(29)}$. A complete ban would be reasonable only: (i) where the FDA determined that no evidence supports a health claim; or (ii) where the claim rests on qualitatively weak evidence, such as 'only one or two old studies ${ }^{\text {,(29) }}$. In either case, the government would have to demonstrate with 'empirical evidence that consumers would be deceived by the use of the claim if accompanied by a disclaimer' ${ }^{\text {(29) }}$. One court summed up by stating that the First Amendment expresses a 'clear preference for disclosure over suppression of commercial speech'(29).

In response to these court decisions, the FDA has permitted qualified health claims for both dietary supplements and conventional foods under a lower 'credible evidence' standard ${ }^{(30)}$. The agency has not actually approved such claims; it has, instead, chosen merely to permit them by exercising its enforcement discretion not to bring enforcement actions against claims that meet the credible evidence standard ${ }^{(4,30)}$. The agency has also developed qualifying language for health claims based on the level of scientific evidence that supports them ${ }^{(31,32)}$.

The application of First Amendment commercial speech doctrine to food-label regulation is a relatively new development, and many important questions have yet to be addressed by the courts. At this point, however, it is well established that FDA regulations regarding nutrition and health claims on both conventional foods and dietary supplements must conform to the US Supreme Court's 'reasonable fit' test. Lower courts have interpreted this test to mean that the agency may require qualifications and disclaimers on claims but may not ban such claims unless it can prove that the claim is unsupported by any scientific evidence or is supported only by qualitatively weak evidence ('only one or two old studies') and that consumers would be deceived by the use of the claim if accompanied by a disclaimer. While this doctrine was developed in litigation concerning FDA regulation of health claims on dietary supplements, nothing in the courts' opinions limits the analysis to either health claims or dietary supplements. No one has yet suggested that First Amendment restrictions on health claims would not apply to other types of nutrition claims, and the FDA itself, in response to the courts' rulings, adjusted its regulatory standards not only for dietary supplements but also for conventional foods.

\section{A ban on all front-of-package nutrition and health claims would be unconstitutional}

Nestle and Ludwig's proposal to ban all front-of-package nutrition and health claims on conventional foods would be a radical change in policy. As we have seen, current federal regulations allow several different types of such claims: structure/function statements; dietary guidance statements; health claims that meet agency approval under a credible evidence standard; and various types of nutrient content claims, including simple quantitative statements about nutrient content provided they are accurate, and descriptive and evaluative statements about nutrient content and nutritional value so long as they conform to FDA definitions. First Amendment restrictions 
on FDA regulation of nutrition and health claims render Nestle and Ludwig's proposal for a ban on all such claims unconstitutional. To begin with, an outright ban on accurate quantitative statements (e.g. '200 mg of sodium') or descriptive statements that conform to current FDA definitions (e.g. 'high in fiber') would be a clear violation of the First Amendment's protection of commercial speech. Under the FDA's own standards, such statements would not be misleading. Furthermore, insofar as the FDA could prevent evaluative statements, such as the new generation of symbols and nutritional rating schemes, from being misleading by establishing definitions and minimum standards - as it has done for use of the term 'healthy' to characterize the overall nutritional value of a food - any outright ban on such claims would likely be considered overbroad in violation of the 'reasonable fit' test. As for health claims, structure/function claims and general dietary guidance, it appears that the courts will allow the FDA to prohibit such claims only on a case-by-case basis where the agency can demonstrate that little or no scientific evidence supports a claim and that disclaimers and qualifications fail to render the claim non-misleading.

An outright ban on all front-of-package nutrition and health claims might well be the most effective and efficient way to crack down on misleading food labels and to promote healthier dietary habits. The First Amendment, however, requires that the government use less restrictive means to achieve these important goals.

\section{Acknowledgements}

The author received no financial support for the writing of the present commentary beyond his regular academic salary and he has no professional or financial relationships with any food industry or food policy advocacy organization.

\section{References}

1. Nestle M \& Ludwig DS (2010) Front-of-package food labels: public health or propaganda? JAMA 303, 771-772.

2. Federal Food, Drug, and Cosmetic Act $\S$ 403, 21 U.S.C. $\S 343(\mathrm{r})$ (West 2006).

3. 21 C.F.R. $\S 101.14$ (2009).

4. US Food and Drug Administration, Department of Health and Human Services (2007) Guidance for industry and FDA: Dear Manufacturer, Letter Regarding Food Labeling (January 2007). http://www.fda.gov/Food/GuidanceComplianceRegulatory Information/GuidanceDocuments/FoodLabelingNutrition/ ucm053425.htm (containing non-binding recommendations).
5. 21 C.F.R. $\S 101.70$ (2009).

6. Food Labeling (1993) General Requirements for Health Claims for Food, 58 Fed. Reg. 2478, 2484 (Jan. 6, 1993).

7. 21 C.F.R. $\S 101.13$ (2009).

8. Shapiro R (1995) A comprehensive review of the nutrition labeling and education act regulations. In Nutrition Labeling Handbook, pp. 126-226 [R Shapiro, editor]. New York: Marcel Dekker.

9. 21 C.F.R. $\$ 101.54$ (2009)

10. 21 C.F.R. $\$ 101.55$ (2009).

11. 21 C.F.R. $\$ 101.56$ (2009).

12. 21 C.F.R. $\S 101.57$ (2009).

13. 21 C.F.R. $\$ 101.58$ (2009)

14. 21 C.F.R. $\$ 101.59$ (2009).

15. 21 C.F.R. $\$ 101.60$ (2009).

16. 21 C.F.R. $\$ 101.61$ (2009).

17. 21 C.F.R. $\$ 101.62$ (2009).

18. US Department of Health and Human Services, Food and Drug Administration (2008) Office of Nutrition, Labeling and Dietary Supplements. Guidance For Industry: A Food Labeling Guide. http://www.fda.gov/Food/Guidance ComplianceRegulatoryInformation/GuidanceDocuments/ FoodLabelingNutrition/FoodLabelingGuide/default.htm\# Introduction

19. 21 C.F.R. $\S 101.69$ (2009).

20. 21 C.F.R. $\$ 101.12(2009)$

21. 63 Fed. Reg. 26978-02, 26979 (15 May 1998).

22. Final Rule (2009) 59 Fed. Reg. 24232 at 24235 (10 May 1994) (codified at 21 C.F.R. $\S 101$ ).

23. 21 C.F.R. $\S 101.65(d)(2)(2009)$.

24. Neuman W (2009) For your health, Froot Loops, New York Times, 5 September, B1.

25. Connecticut Attorney General's Office (2009) Attorney General investigates "Smart Choices" food labels that endorse mayonnaise and sugary cereals. http://www.ct. gov/AG/cwp/view.asp?A $=3673 \& Q=448878$

26. Taylor MR (2009) Letter to the Smart Choices Program. http://www.fda.gov/Food/LabelingNutrition/LabelClaims/ ucm180146.htm

27. Pearson v. Shalala, 164 F.3d 650 (D.C. 1999).

28. Central Hudson v. Public Service Commission of New York 447 US 557, 566 (1980).

29. Whitaker v. Thompson, 248 F. Suppl. 2d 1 (D.D.C. 2002).

30. US Department of Health and Human Services, Food and Drug Administration (2006) Center for Food Safety and Applied Nutrition. Guidance for Industry: FDA's Implementation of "Qualified Health Claims": Questions and Answers: Final Guidance. http://www.fda.gov/Food/Guidance ComplianceRegulatoryInformation/GuidanceDocuments/Food LabelingNutrition/UCM053843.htm

31. Department of Health and Human Services, Food and Drug Administration (2003) Center for Food Safety and Applied Nutrition. Guidance for industry: interim procedures for qualified health claims in the labeling of conventional human food and human dietary supplements. http://www. fda.gov/Food/GuidanceComplianceRegulatoryInformation/ GuidanceDocuments/FoodLabelingNutrition/ucm053832.htm

32. Lytton $\mathrm{T}$ (2010) Signs of change or clash of symbols?: FDA regulation of nutrient profile labeling. Health Matrix 20, 93-144. 